\title{
RATIO OF PATIENT'S HEIGHT TO THYROMENTAL DISTANCE (RHTMD) COMPARED TO THYROMENTAL DISTANCE FOR PREDICTION OF DIFFICULT INTUBATION
}

\author{
Shivakumar P. S1, Sarvesh N. K², Vinuta Patil ${ }^{3}$, Sagar G. $C^{4}$, Sreeharsha Sirigeri ${ }^{5}$, Pradhan Monnaiah K6, Gundappa R. $S^{7}$ \\ ${ }^{1}$ Senior Resident, Department of Anaesthesiology, MVJ Medical College and Research Centre, Bangalore. \\ ${ }^{2}$ Assistant Professor, Department of Anaesthesiology, DM Wayanad Institute of Medical Sciences, Wayanad. \\ ${ }^{3}$ Assistant Professor, Department of Anaesthesiology, DM Wayanad Institute of Medical Sciences, Wayanad. \\ ${ }^{4}$ Assistant Professor, Department of Anaesthesiology, DM Wayanad Institute of Medical Sciences, Wayanad. \\ ${ }_{5}^{5}$ Assistant Professor, Department of Anaesthesiology, DM Wayanad Institute of Medical Sciences, Wayanad. \\ ${ }^{6}$ Senior Resident, Department of Anaesthesiology, DM Wayanad Institute of Medical Sciences, Wayanad. \\ ${ }^{7}$ Senior Resident, Department of Anaesthesiology, DM Wayanad Institute of Medical Sciences, Wayanad.
}

ABSTRACT

\section{BACKGROUND AND OBJECTIVE}

Preoperative evaluation is important in the detection of patients at risk for difficult tracheal intubation. The purpose of the present study was to evaluate and compare the accuracies of the Ratio of Patient's Height to TMD (Ratio of height to TMD = RHTMD), with TMD and Modified Mallampati classification (MP) in the prediction of difficult tracheal intubation.

\section{METHODS}

170 apparently normal ASA I and II patients who were undergoing elective surgeries under General Anaesthesia (GA) were included in the study. The MP, TMD and RHTMD were determined in each patient preoperatively and Cormack-Lehane (CL) grading was assessed during laryngoscopy. TMD $\leq 6.5 \mathrm{~cm}$, RHTMD $>25$ and MP class III and IV were considered difficult intubation; these values were compared with CL grading. CL grade III and IV were considered as difficult intubation. The optimal predictive value was chosen using a Receiver Operating Characteristic (ROC) curve. The areas under the ROC curves (AUC) of TMD and RHTMD were compared to determine the performance of the different predictive tests used. The sensitivity, specificity and positive and negative predictive values of each of the predictive tests were calculated according to standard formulae.

\section{RESULTS}

Difficult intubation occurred in 6 out of 170 patients (3.5\%) in the study. In our study the Area Under Curve (AUC) of RHTMD was 0.87; it is significantly higher than TMD (0.184) and MP test (0.726) indicating a more accurate prediction of RHTMD. A P value was calculated based on AUC; it shows that RHTMD had a higher and significantly better predictive value than MP classification and TMD with $P$ value of 0.028

\section{CONCLUSION}

The Ratio of Height to Thyromental Distance has a better predictive value than Thyromental Distance and Modified Mallampati classification. Ratio of Height to Thyromental Distance may represent a useful means of achieving a faster, simpler and more accurate predictor of difficult airway.

\section{KEYWORDS}

Difficult Airway; Modified Mallampati Classification; Thyromental Distance; Ratio of Height to Thyromental Distance; Cormack and Lehane Grading.

HOW TO CITE THIS ARTICLE: Shivakumar PS, Sarvesh NK, Patil V, et al. Ratio of patient's height to thyromental distance (RHTMD) compared to thyromental distance for prediction of difficult intubation. J. Evolution Med. Dent. Sci. 2016;5(63):4462-4467, DOI: $10.14260 /$ jemds/2016/1018

\section{INTRODUCTION}

Failure in managing airway is the most significant cause of mortality and morbidity in anaesthetised patients. ${ }^{1}$ Incidence of difficult intubation is $5.8 \%$ in patients undergoing surgery; however, it still accounts for significant proportion of adverse anaesthetic outcomes in clinical practice. ${ }^{2}$

Financial or Other, Competing Interest: None.

Submission 22-06-2016, Peer Review 22-07-2016,

Acceptance 28-07-2016, Published 08-08-2016.

Corresponding Author:

Dr. Shivakumar P. S,

S/o Subbareddy P.S,

Pathakote,

Pathapalya Post,

Bagepalli Taluk,

Chikballapur-561212.

E-mail:drsarveshnk@yahoo.com

DOI: $10.14260 /$ jemds/2016/1018
The single largest source of unfavourable outcome in the ASA (American Society of Anaesthesiologists) closed claim study was for adverse respiratory episodes which accounted for $34 \%$ liability claims, of which difficult tracheal intubation was the culprit in $50 \% .^{3}$ So, preoperative evaluation is important in the detection of patients at risk for difficult airway management.

Although, many advances have been made and many methods have been used to overcome unanticipated difficult airway (Difficult laryngoscopic intubation), the existing bedside tests such as:

- Patil's measurement of Thyromental Distance (TMD). ${ }^{4}$

- Modified Mallampati classification. ${ }^{5}$

- Wilson scoring system. ${ }^{6}$

Have been shown in various studies to have high false positive rates, which detracts from their usefulness. 
So there is a need for the test which is quick and easy to perform, which is highly sensitive (so that majority of difficult cases can be identified) and highly specific (so that false positive rate will be low when the test is used routinely).

However, one of the tests proposed to predict difficult airway, Thyromental Distance (TMD) varies with patient's size. TMD has been adjusted for patient's height for predicting difficult airway.7,8,9 We in our prospective study try to evaluate the capability of the Ratio of Patient's Height to Thyromental Distance (RHTMD) for predicting ease of difficult intubation.

\section{AIMS AND OBJECTIVES}

The study is an attempt to find an airway index by making simple measurements to anticipate a difficult airway. This study is an attempt to compare Ratio of Patient's Height to Thyromental Distance (RHTMD), Thyromental Distance and Modified Mallampati classification for predicting difficult intubation.

\section{MATERIALS AND METHODS}

The study was conducted for a duration of six months after obtaining Institutional Review Board (Ethical Committee) approval. Written informed consent of patient was obtained before including the patient in the study. The study was a prospective clinical study. The first 170 consecutive cases coming to the Hospital during the study period satisfying the inclusion and exclusion criteria was included in the study.

\section{Sample Size}

Sample size was calculated using the following formula.

\section{Formula}

$$
\mathrm{n}=\frac{\mathrm{t}^{2} \times \mathrm{p}(1-\mathrm{p})}{\mathrm{m}^{2}}
$$

$$
\begin{array}{ll}
\mathrm{n}= & \text { Required sample size. } \\
\mathrm{t}= & \text { Confidence level at } 95 \% \text { (Standard value of 1.96) } . \\
\mathrm{p}= & \text { Estimated prevalence of difficult intubation } \\
& =5.8 \%=0.058 . \\
\mathrm{m}= & \text { Margin of error at } 5 \% \text { (Standard value of } 0.05) \\
& =0.05 .
\end{array}
$$

Sample size $=\{1.96 \times 0.058(1-0.058)\} / 0.0025=83.956$ rounded to 85 .

Since we want to compare two methods, a sample size of 170 cases was included in the study.

\section{Inclusion Criteria}

- $\quad$ All patients aged above 18 of either sex.

- Patients belonging to ASA (American Society of Anaesthesiologist) Grade I and II Physical status.

- Patients undergoing elective surgery under general anaesthesia with endotracheal intubation.

\section{Exclusion Criteria}

- Pregnant patients.

- Patients with mouth opening $<3 \mathrm{~cm}$.

- $\quad$ Obese patients with Body Mass Index $>30$.

- Patients coming for emergency surgery.

- Patients with midline neck swellings.

- Allergies or contraindications for any drugs used in the study.

\section{Preoperative Evaluation}

Detailed examination and routine investigations including laboratory tests complete blood count, haemoglobin, serum biochemistry profile and urine analysis, electrocardiogram, chest X-ray was taken when indicated.

\section{Preanaesthetic Visit}

Thyromental distance was measured as straight distance between the thyroid notch and the lower border of mental prominence with the head fully extended and the mouth closed using a rigid ruler. The distance was rounded to the nearest 0.5 $\mathrm{cm}$.

Height of patient was measured in centimetres with the patient standing straight by side of wall with heel touching wall and will be rounded to nearest $1 \mathrm{~cm}$. Ratio of Height to Thyromental Distance calculated accordingly. Modified Mallampati classification was assessed along with this.

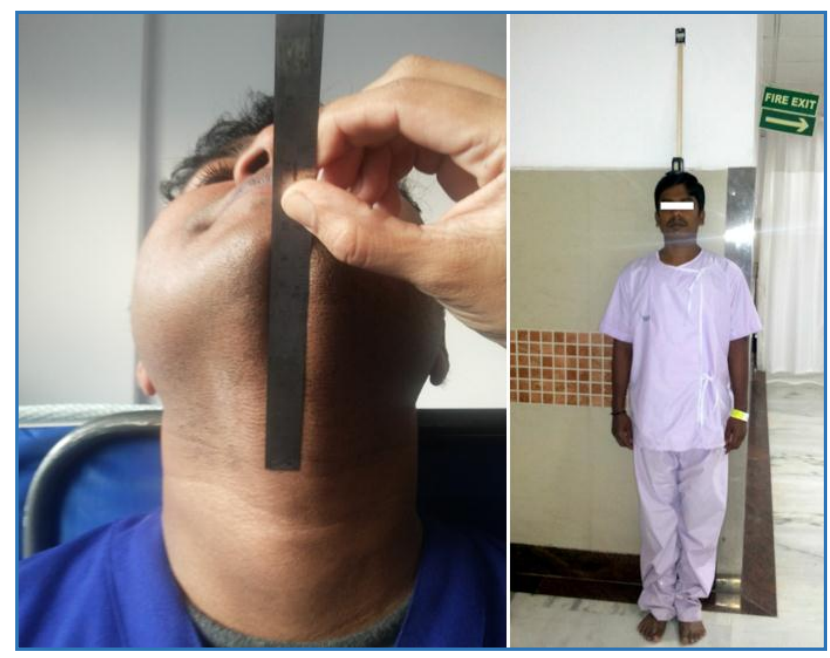

Fig. 1: Measurement of TMD on Left and Measurement of Height on the Right

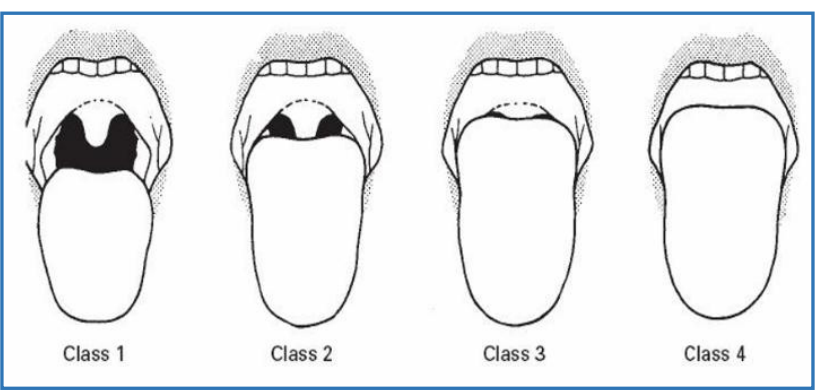

Fig. 2: Modified Mallampati Classification

Class I: Uvula, faucial pillars and soft palate visible. Class II: Faucial pillars and soft palate visible.

Class III: Only soft palate visible.

Class IV: Only hard palate visible.

\section{Intraoperative}

After pre-oxygenation for 3 minutes, all patients were induced using propofol $2 \mathrm{mg} / \mathrm{kg}$ and paralysed using suxamethonium $1.5 \mathrm{mg} / \mathrm{kg}$ to facilitate good orotracheal intubation. Laryngoscopy was performed after one minute.

The head was placed in sniffing position on a head ring or a pillow and a Macintosh blade number 3 was used by a conventionally trained anaesthesiologist. 
Glottic visualisation was assessed by using modified Cormack and Lehane classification without external laryngeal manipulation. This classification involves 4 grades of glottic visualisation:

Grade I: Full glottic exposure.

Grade II: Only posterior commissure of the glottis seen.

Grade III: Only epiglottis seen.

Grade IV: No view of larynx.

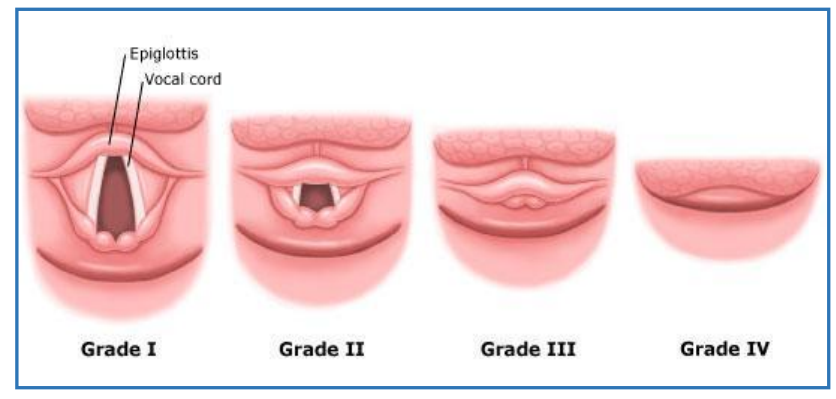

Fig. 3: Cormack and Lehane Classification

External laryngeal pressure (Backward-upward-rightward pressure) if required was permitted after evaluation for insertion of an endotracheal tube. We were able to intubate all patients using external pressure.

Cormack and Lehane grades 3 and 4 were defined as difficult intubation in this study. The preoperative assessment data and laryngoscope findings were used together to evaluate the accuracy of test RHTMD in predicting difficult intubation. In this study, a cut-off value of $\geq 25$ for RHTMD. ${ }^{8}$ and $\leq 6.5 \mathrm{~cm}$ for TMD. ${ }^{9}$ was taken to predict difficult airway.

The sensitivity, specificity and positive and negative predictive values of each test calculated according to standard formula.

\section{Statistical Terms}

- True positive $=\mathrm{a}$ difficult intubation that had been predicted to be difficult.

- False positive $=$ an easy intubation that had been predicted to be difficult.

- True negative = an easy intubation that had been predicted to be easy.

- $\quad$ False negative $=\mathrm{a}$ difficult intubation that had been predicted to be easy.

- Sensitivity $=$ the percentage of correctly predicted difficult intubations as a proportion of all intubations that were truly difficult.

- $\quad$ Specificity $=$ the percentage of correctly predicted easy intubations as a proportion of all intubations that were truly easy.

- $\quad$ Positive predictive value $=$ the percentage of correctly predicted difficult intubations as a proportion of all predicted difficult intubations.

- $\quad$ Negative predictive value $=$ the percentage of correctly predicted easy intubations as a proportion of all predicted easy intubations.

- $\quad$ Accuracy = the percentage of correctly predicted easy or difficult intubations as a proportion of all intubations.

\section{RESULTS}

The chi-square test was used for statistical analysis of variables.

\begin{tabular}{|c|c|c|}
\hline Gender & Frequency & Percent \\
\hline Male & 88 & $51.7 \%$ \\
\hline Female & 82 & $48.3 \%$ \\
\hline Total & $\mathbf{1 7 0}$ & $\mathbf{1 0 0} \%$ \\
\hline \multicolumn{2}{|c|}{ Table 1: Gender Distribution } \\
\hline
\end{tabular}

\begin{tabular}{|c|c|c|}
\hline ASA & Frequency & Percent \\
\hline I & 128 & 75.3 \\
II & 42 & 24.7 \\
\hline Total & $\mathbf{1 7 0}$ & $\mathbf{1 0 0 . 0}$ \\
\hline \multicolumn{2}{|c|}{ Table 2: Distribution of ASA in Study Population } \\
\hline
\end{tabular}

\begin{tabular}{|c|c|c|}
\hline Age in Years & Frequency & Percent \\
\hline$<25$ & 34 & 20 \\
$26-35$ & 31 & 18.2 \\
$36-45$ & 41 & 24.1 \\
$46-55$ & 42 & 24.7 \\
$56-65$ & 20 & 11.8 \\
$>65$ & 2 & 1.2 \\
Total & $\mathbf{1 7 0}$ & $\mathbf{1 0 0 . 0}$ \\
\hline \multicolumn{3}{|c|}{ Table 3: Age Distribution } \\
\hline
\end{tabular}

\begin{tabular}{|c|c|c|}
\hline $\begin{array}{c}\text { Modified } \\
\text { Mallampati } \\
\text { Classification }\end{array}$ & Frequency & Percent \\
\hline I & 92 & 54.1 \\
II & 61 & 35.9 \\
III & 17 & 10 \\
IV & 0 & 0 \\
Total & $\mathbf{1 7 0}$ & $\mathbf{1 0 0 . 0}$ \\
\hline \multicolumn{2}{|c|}{ Table 4: Distribution of Modified Mallampati } \\
\hline \multicolumn{2}{|c|}{ Class in the Study Population } \\
\hline
\end{tabular}

\begin{tabular}{|c|c|c|}
\hline TMD & Frequency & Percent \\
\hline$\leq 6.5$ & 36 & 21.2 \\
$>6.5$ & 134 & 78.8 \\
Total & 170 & 100.0 \\
\hline \multicolumn{3}{|c|}{ Table 5: Distribution of Thyromental } \\
\multicolumn{2}{|c|}{ Distance in the Study Population } \\
\hline
\end{tabular}

\begin{tabular}{|c|c|c|}
\hline RHTMD & Frequency & Percent \\
\hline$<25$ & 161 & 94.7 \\
\hline$\geq 25$ & 9 & 5.3 \\
\hline Total & $\mathbf{1 7 0}$ & $\mathbf{1 0 0 . 0}$ \\
\hline Table 6: Distribution of Ratio of Height to Thyromental \\
Distance in the Study Population \\
\hline
\end{tabular}

\section{Cormack and Lehane Grading}

\begin{tabular}{|c|c|c|}
\hline $\begin{array}{c}\text { Cormack and } \\
\text { Lehane Grading }\end{array}$ & Frequency & Percent \\
\hline I & 139 & 81.8 \\
II & 25 & 14.7 \\
III & 6 & 3.5 \\
IV & 0 & 0 \\
Total & $\mathbf{1 7 0}$ & $\mathbf{1 0 0 . 0}$ \\
\hline \multicolumn{2}{|c|}{ Table 7: Distribution of Cormack and Lehane Grading } \\
in the Study Population \\
\hline
\end{tabular}




\begin{tabular}{|c|c|c|c|c|c|c|c|c|c|}
\hline \multirow{2}{*}{\multicolumn{2}{|c|}{$\begin{array}{c}\text { CL } \\
\text { Grade/MP } \\
\text { Grade }\end{array}$}} & \multicolumn{6}{|c|}{ CL Grading } & \multirow{2}{*}{\multicolumn{2}{|c|}{ Total }} \\
\hline & & \multicolumn{2}{|c|}{ I } & \multicolumn{2}{|c|}{ II } & \multicolumn{2}{|c|}{ III } & & \\
\hline \multirow{6}{*}{ MP } & \multirow{2}{*}{ I } & 82 & $89.13 \%$ & 9 & $9.7826 \%$ & 1 & $1.09 \%$ & 92 & $100 \%$ \\
\hline & & $58.993 \%$ & & $36 \%$ & & $16.667 \%$ & & & \\
\hline & \multirow{2}{*}{ II } & 47 & $77.049 \%$ & 11 & $18.033 \%$ & 3 & $4.92 \%$ & 61 & $100 \%$ \\
\hline & & $33.813 \%$ & & $44 \%$ & & $50 \%$ & & & \\
\hline & \multirow{2}{*}{ III } & 10 & $58.824 \%$ & 5 & $29.412 \%$ & 2 & $11.8 \%$ & 17 & $100 \%$ \\
\hline & & $7.1942 \%$ & & $20 \%$ & & $33.333 \%$ & & & \\
\hline \multirow{2}{*}{\multicolumn{2}{|c|}{ Total }} & 139 & & 25 & & 6 & & 170 & \\
\hline & & $100 \%$ & & $100 \%$ & & $100 \%$ & & & \\
\hline & & Table 8: D & & $\begin{array}{l}\text { elation } \\
\text { de in } P\end{array}$ & onof & $\begin{array}{l}\text { ampati } \\
\text { Intubati }\end{array}$ & $\therefore$ & & \\
\hline
\end{tabular}

\begin{tabular}{|c|c|c|c|c|c|c|c|c|c|}
\hline \multirow{2}{*}{\multicolumn{2}{|c|}{ CL Grade/TMD }} & \multicolumn{6}{|c|}{ CL Grading } & \multirow{2}{*}{\multicolumn{2}{|c|}{ Total }} \\
\hline & & & & & & & & & \\
\hline \multirow{4}{*}{ TMD } & \multirow{2}{*}{$\leq 6.5$} & 22 & $61.111 \%$ & 12 & $33.333 \%$ & 2 & $5.56 \%$ & 36 & $100 \%$ \\
\hline & & $15.827 \%$ & & $48 \%$ & & $33.333 \%$ & & & \\
\hline & \multirow{2}{*}{$>6.5$} & 117 & $87.313 \%$ & 13 & $9.7015 \%$ & 4 & $2.99 \%$ & 134 & $100 \%$ \\
\hline & & $84.173 \%$ & & $52 \%$ & & $66.667 \%$ & & & \\
\hline \multirow{2}{*}{\multicolumn{2}{|c|}{ Total }} & 139 & & 25 & & 6 & & 170 & \\
\hline & & $100 \%$ & & $100 \%$ & & $100 \%$ & & & \\
\hline \multicolumn{10}{|c|}{$\begin{array}{c}\text { Table 9: Distribution and Correlation by Thyromental Distance with Cormack \& Lehane } \\
\text { Grade in Prediction of Difficult Intubation }\end{array}$} \\
\hline
\end{tabular}

\begin{tabular}{|c|c|c|c|c|c|c|c|c|c|}
\hline \multirow{2}{*}{\multicolumn{2}{|c|}{ CL Grade/RHTMD }} & \multicolumn{6}{|c|}{ CL Grading } & \multirow{2}{*}{\multicolumn{2}{|c|}{ TOTAL }} \\
\hline & & & & & II & & & & \\
\hline \multirow{4}{*}{ RHTMD } & \multirow{2}{*}{$<25$} & 138 & $85.714 \%$ & 22 & $13.665 \%$ & 1 & $0.62 \%$ & 161 & $100 \%$ \\
\hline & & $99.281 \%$ & & $88 \%$ & & $16.667 \%$ & & & \\
\hline & \multirow{2}{*}{$\geq 25$} & 1 & $11.111 \%$ & 3 & $33.333 \%$ & 5 & $55.6 \%$ & 9 & $100 \%$ \\
\hline & & $0.7194 \%$ & & $12 \%$ & & $83.333 \%$ & & & \\
\hline \multirow{2}{*}{\multicolumn{2}{|c|}{ Total }} & 139 & & 25 & & 6 & & 170 & \\
\hline & & 100 & $100 \%$ & & $100 \%$ & & $100 \%$ & & \\
\hline \multicolumn{10}{|c|}{$\begin{array}{l}\text { Table 10: Distribution and Correlation by Ratio of Height to Thyromental Distance with Cormack \& Lehane } \\
\text { Grade in Prediction of Difficult Intubation }\end{array}$} \\
\hline
\end{tabular}

\begin{tabular}{|c|c|c|c|c|c|}
\hline \multirow{2}{*}{\multicolumn{3}{|c|}{ CL Grade/MP Grade }} & \multicolumn{2}{|c|}{ CL Grade } & \multirow{3}{*}{$\begin{array}{r}\text { Total } \\
17\end{array}$} \\
\hline & & & \multirow{2}{*}{$\begin{array}{c}\begin{array}{c}\text { I, II } \\
\text { (Difficult) }\end{array} \\
2 \\
\end{array}$} & \multirow{2}{*}{$\begin{array}{c}\begin{array}{c}\text { III, IV } \\
\text { (Easy) }\end{array} \\
15\end{array}$} & \\
\hline \multirow{2}{*}{ MP } & $\begin{array}{c}\text { I, II } \\
\text { (Difficult) }\end{array}$ & Count & & & \\
\hline & $\begin{array}{c}\text { III, IV } \\
\text { (Easy) }\end{array}$ & Count & 4 & 149 & 153 \\
\hline Total & & Count & 6 & 164 & 170 \\
\hline
\end{tabular}

The sensitivity of Modified Mallampati test was $33.3 \%$ and specificity was $90.8 \%$. The test has a positive predictive value of $11.7 \%$, negative predictive value of $97.3 \%$ and overall accuracy of $88.8 \%$. These values are derived from Table 11 .

\begin{tabular}{|c|c|c|c|c|c|}
\hline \multirow{2}{*}{\multicolumn{3}{|c|}{ CL Grade/TMD }} & \multicolumn{2}{|c|}{ CL Grade } & \multirow{3}{*}{$\begin{array}{r}\text { Total } \\
36 \\
\end{array}$} \\
\hline & & & \multirow{2}{*}{$\begin{array}{c}\begin{array}{c}\text { I, II } \\
\text { (Difficult) }\end{array} \\
2 \\
\end{array}$} & \multirow{2}{*}{$\begin{array}{c}\begin{array}{c}\text { III, IV } \\
\text { (Easy) }\end{array} \\
34 \\
\end{array}$} & \\
\hline \multirow{2}{*}{ TMD } & $\leq 6.5$ (Difficult) & Count & & & \\
\hline & $>6.5$ (Easy) & Count & 4 & 130 & 134 \\
\hline Total & & Count & 6 & 164 & 170 \\
\hline
\end{tabular}

The sensitivity of TMD was $33.3 \%$ and specificity was $79.2 \%$. The test has a positive predictive value of $5.5 \%$, negative predictive value of $97 \%$ and overall accuracy of $77.6 \%$. These values were derived from Table 12 . 


\begin{tabular}{|c|c|c|c|c|c|}
\hline \multirow{2}{*}{\multicolumn{3}{|c|}{ CL Grade/RHTMD }} & \multicolumn{2}{|c|}{ CL Grade } & \multirow{3}{*}{$\begin{array}{r}\text { Total } \\
9\end{array}$} \\
\hline & & & \multirow{2}{*}{$\begin{array}{c}\begin{array}{c}\text { I, II } \\
\text { (Difficult) }\end{array} \\
5\end{array}$} & \multirow{2}{*}{$\begin{array}{c}\begin{array}{c}\text { III, IV } \\
\text { (Easy) }\end{array} \\
4\end{array}$} & \\
\hline \multirow{2}{*}{ RHTMD } & $\geq 25$ (Difficult) & Count & & & \\
\hline & < 25 (Easy) & Count & 1 & 160 & 161 \\
\hline Total & & Count & 6 & 164 & 170 \\
\hline
\end{tabular}

The sensitivity of RHTMD was $83.3 \%$ and specificity was $97.5 \%$. The test has a positive predictive value of $55.5 \%$, negative predictive value of $99.3 \%$ and overall accuracy of 97\%. These values were derived from Table 13.

\begin{tabular}{|c|c|c|c|}
\hline $\begin{array}{c}\text { Statistical Tools/Difficult } \\
\text { Intubation Assessment } \\
\text { Tools }\end{array}$ & MP & TMD & RHTMD \\
\hline Sensitivity & 33.3 & 33.3 & 83.3 \\
\hline Specificity & 90.8 & 79.2 & 97.5 \\
\hline Positive predictive value & 11.7 & 5.5 & 55.5 \\
\hline Negative predictive value & 97.3 & 97 & 99.3 \\
\hline Accuracy & 88.8 & 77.6 & 97 \\
\hline \multicolumn{4}{|c|}{$\begin{array}{c}\text { Table 14: Comparison of Statistical Tools of Different } \\
\text { Tests in Predicting Difficult Intubation }\end{array}$} \\
\hline
\end{tabular}

RHTMD has better sensitivity, specificity, positive predictive value, negative predictive value and accuracy compared to TMD and MP as shown in Table 14.

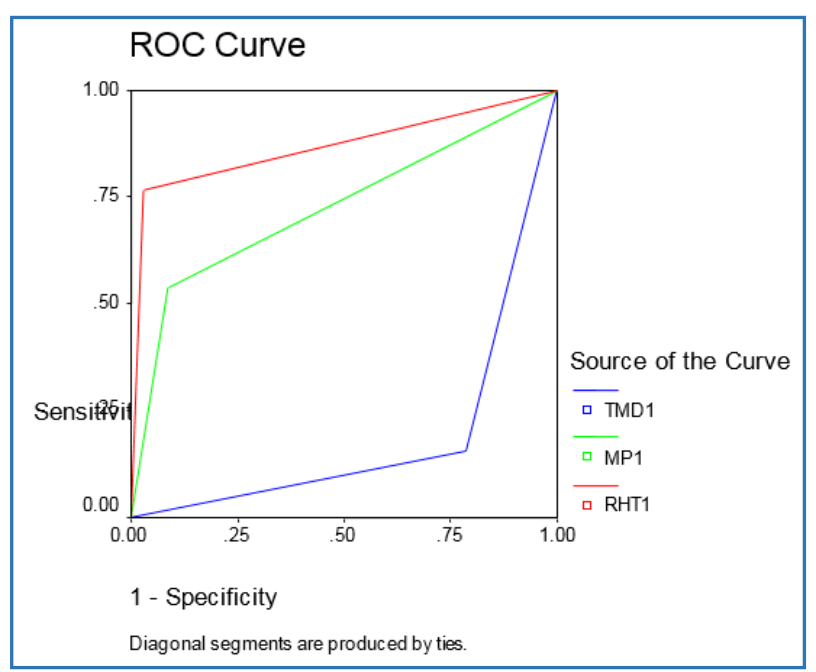

Fig. 4: Receiver Operating Characteristic (ROC) Curve of Different Tests

\begin{tabular}{|c|c|}
\hline RHTMD & .870 \\
MP & .726 \\
TMD & .184 \\
\hline Table 15: Area Under the Curve (AUC) (p value = 0.028) \\
\hline
\end{tabular}

The Area Under Curve (AUC) of RHTMD was 0.870; it is significantly higher than TMD (0.184) and MP classification (0.726) indicating a more accurate prediction of RHTMD as shown in Table 15 and Figure 4.

\section{DISCUSSION}

In earlier days, anaesthesia was induced by anaesthetic vapours given through a face mask. Due to inability to maintain a patent airway, adequate depth of anaesthesia, its associated complications, anaesthetic practice by securing the airway by an endotracheal tube was devised.
The significance of difficult or failed tracheal intubation is well recognized as a major cause of morbidity and mortality in anaesthetic practice as per ASA closed claim study. The need to predict potentially difficult tracheal intubation has received more importance but with limited success. Unanticipated difficult intubation is a risk to patient's life and a challenge to the skill of the anaesthesiologist.

Many anatomical and pathological variables have been identified and have been suggested to be useful in anticipating a difficult airway. These factors have limitations because of wide variations in the incidence of difficult intubation, interobserver variability and inadequate statistical power of the currently measured variables.

There is no test which can be considered foolproof to predict a difficult intubation. So there is a need for a test which is quick and easy to perform, which is highly sensitive (So that majority of difficult cases can be identified) and highly specific (So that false positive rate will be low when the test is used routinely). Any test devised should be easy to perform and interpret at the bedside.

In our study, study population consisted of 170 ASA Grade I and II patients with apparently normal airway who underwent surgical procedures under general anaesthesia.

In our study, the prediction of difficult intubation was done by MP, TMD, RHTMD during preoperative assessment and correlating it to Cormack-Lehane Laryngoscopy grading at intubation. MP Class III and IV, TMD $\leq 6.5 \mathrm{~cm}$, RHTMD $\geq 25$ and CL grade III and IV was considered as difficult intubation. Among these CL grading was considered as gold standard, other tests were compared with this.

In our study, incidence of difficult intubation was $3.5 \%$ as shown in Table 7, which is comparable to study conducted by Shiga et $\mathrm{al}^{2}$ (2005), in which incidence of difficult intubation was $5.8 \%$.

In our study, the sensitivity of Modified Mallampati test was $33.3 \%$ and specificity was $90.8 \%$. The test has a positive predictive value of $11.7 \%$, negative predictive value of $97.3 \%$ and overall accuracy of $88.8 \%$ as shown in Table 8 and Table 11. We had lower sensitivity and higher specificity as compared to studies conducted by Iohom et al,10 in which sensitivity of Mallampati classification was found to be $43 \%$ and specificity to be $93 \%$ and Oates et al ${ }^{11}$ (1991) in which sensitivity of Mallampati was found to be $42 \%$ and specificity to be $84 \%$.

In our study, the sensitivity of TMD was $33.3 \%$ and specificity was $79.2 \%$. The test has a positive predictive value of $5.5 \%$, negative predictive value of $97 \%$ and overall accuracy of $77.6 \%$ as shown in Table 9 and Table 12, which is comparable to studies conducted by Tse et al ${ }^{12}$ (1995) in which sensitivity and specificity of TMD were 33\% and $80 \%$ respectively and Iohom et al 10 in which sensitivity of Thyromental distance was found to be $45 \%$ and specificity to be $95 \%$. 
In our study, the sensitivity of RHTMD was $83.3 \%$ and specificity was $97.5 \%$. The test has a positive predictive value of $55.5 \%$, negative predictive value of $99.3 \%$ and overall accuracy of $97 \%$ as shown in Table 10 and Table 13 . We had higher sensitivity and specificity compared to studies conducted by Krobbuaban et al ${ }^{8}$ (2005), in which sensitivity and specificity of RHTMD was $83 \%$ and $65 \%$ respectively and Schmitt et al7 (2002), in which sensitivity and specificity of RHTMD was $81 \%$ and $90 \%$ respectively.

We used the analysis of ROC curves to assess and compare the overall performance of the predictive tests. This methodology is widely used to evaluate the performance of diagnostic tests.

In our study, the Area Under Curve (AUC) of RHTMD was 0.870; it is significantly higher than TMD (0.184) and MP classification (0.726) indicating a more accurate prediction of RHTMD as shown in Table 15 and Figure 4. A P value was calculated based on AUC; it shows that RHTMD had a higher and significantly better predictive value than MP classification and TMD with $P$ value of 0.028 , which is comparable to studies conducted by Schmitt et $\mathrm{al}^{7}$ (2002) and Krobbuaban et $\mathrm{al}^{8}$ (2005).

The results clearly demonstrated that the RHTMD has a higher predictive value compared to MP and TMD. This result is not unexpected since the RHTMD takes individual proportions into account. The ease of calculation using routinely measured vital parameters (Weight and Height) and less time consuming bedside measurements (TMD) makes it a handy tool for prediction of difficult airway.

\section{CONCLUSION}

This study highlights the importance of a new, simple, yet very useful and important test involving measurement of external anatomic structures in predicting a difficult intubation. The specificity and sensitivity of Ratio of Patient's Height to Thyromental Distance outperformed Thyromental Distance and Modified Mallampati classification. Though Modified Mallampati classification has its own significance as a sole predictor of difficult airway due to soft tissue structure, Ratio of patient's height to thyromental distance as an additional tool can be very useful as both soft tissue and bony factors of difficult airway are equally addressed.

\section{REFERENCES}

1. Aitkenhead AR. Injuries associated with anaesthesia. A global perspective. Br J Anaesth 2005;95(1):95-109.

2. Shiga $T$, Wajima $Z$, Inoue $T$, et al. Predicting difficult intubation in apparently normal patients: a meta-analysis of bedside screening test performance. Anesthesiology 2005;103(2):429-37.

3. Domino KB, Caplan RA, Morray JP, et al. The ASA Closed Claims Project 2007:pp 236.

4. Patil VU, Stehling LC, Zauder HL. Fiberoptic endoscopy in anesthesia. Chicago: Year Book Medical Publishers 1983:79.

5. Mallampati SR, Gatt SP, Gugino LD, et al. A clinical sign to predict difficult tracheal intubation: a prospective study. Can Anaesth Soc J 1985;32(4):429-34.

6. Wilson ME, Speigelhalter D, Robertson JA, et al. Predicting difficult intubation. Br J Anaesth 1988;61(2):211-6.

7. Schmitt HJ, Kirmse M, Radespiel-Troger M. Ratio of patient's height to thyromental distance improves prediction of difficult laryngoscopy. Anaesth Intensive Care 2002;30(6):763-5.

8. Krobbuaban B, Diregpoke S, Kumkeaw S, et al. The predictive value of the height ratio and thyromental distance: four predictive tests for difficult laryngoscopy. Anesth Analg 2005;101(5):1542-5.

9. Krishna HM, Agarwal M, Dali JS, et al. Role of ratio of patient's height to thyromental distance for prediction of difficult airway in Indian population. J Clin Pharmacol 2005;21(3):257-60.

10. Iohom G, Ronayne M, Cunningham AJ. Prediction of difficult tracheal intubation. Eur J Anaesthesiol 2003;20(1):31-6.

11. Oates JD, Macleod AD, Oates PD, et al. Comparison of two methods for predicting difficult intubation. Br J Anaesth 1991;66(3):305-9.

12. Tse JC, Rimm EB, Hussain A. Predicting difficult endotracheal intubation in surgical patients scheduled for general anesthesia: a prospective blind study. Anesth Analg 1995;81(2):254-8. 